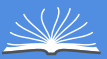

Global Journals Inc.

की

\title{
Prospects of Transitioning to a New Model for Socioeconomic System Organization (Noonomy)
}

By S.D. Bodrunov

Abstract- The current model of the socioeconomic system is plagued by a number of imperfections which tend to escalate with the passage of time. Attempts at resolving inherent issues and contradictions under the existing scientific paradigms have proven futile. It is hardly an exaggeration to state that the modern academic thought has reached an impasse in its efforts to explain some emergent transformations from the perspective of dominant economic theories. Thus, there is an objective need for the development of a new viable model for socioeconomic system organization. Instead of accounting for minute circumstances, the model should rely on long-term fundamental system dynamics. The paper seeks to identify such a model and provide the theoretical substantiation of its core characteristics. S.D. Bodrunov incorporates Marxist and institutionalist approaches to economic analysis and conventional universal methods applied in social and economic sciences and the humanities.

Keywords: noo-society, noonomy, socioeconomic system, fourth industrial revolution, economic evolution, material production, reindustrialization, economic policy.

GJHSS-A Classification: FOR Code: 419999

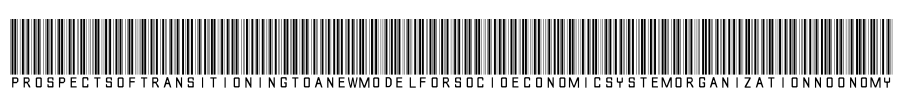

Strictly as per the compliance and regulations of:

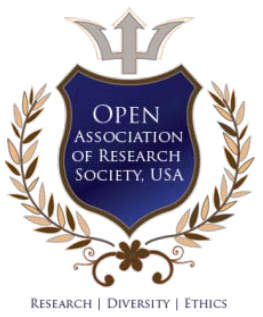

(C) 2019. S.D. Bodrunov. This is a research/review paper, distributed under the terms of the Creative Commons AttributionNoncommercial 3.0 Unported License http://creativecommons.org/licenses/by-nc/3.0/), permitting all non-commercial use, distribution, and reproduction in any medium, provided the original work is properly cited. 


\title{
Prospects of Transitioning to a New Model for Socioeconomic System Organization (Noonomy)
}

\author{
S.D. Bodrunov
}

\begin{abstract}
The current model of the socioeconomic system is plagued by a number of imperfections which tend to escalate with the passage of time. Attempts at resolving inherent issues and contradictions under the existing scientific paradigms have proven futile. It is hardly an exaggeration to state that the modern academic thought has reached an impasse in its efforts to explain some emergent transformations from the perspective of dominant economic theories. Thus, there is an objective need for the development of a new viable model for socioeconomic system organization. Instead of accounting for minute circumstances, the model should rely on long-term fundamental system dynamics. The paper seeks to identify such a model and provide the theoretical substantiation of its core characteristics. S.D. Bodrunov incorporates Marxist and institutionalist approaches to economic analysis and conventional universal methods applied in social and economic sciences and the humanities. The study models the main characteristics of the promising trajectory of the socioeconomic system's further historical evolution which comprisesthe modern society based on the traditional economy, new industrial society of the second generation (NIS.2) based on knowledge capacity and intensity of production, and noo-society based on the noonomy. The author also explores the main features of promising models for
\end{abstract}

socioeconomic system organization, conditions required for transitioning to such models and issues which need to be resolved to ensure a successful transition. Bodrunov shows that a key factor behind the transformation is the acceleration of innovative and technological development which warrants special attention to industrial (material) production. Empirical data and theoretical analysis are used to disprove the concept of the postindustrial society and underpin the conclusion on the importance of pursuing reindustrialization on a qualitatively new foundation reliant on knowledge intensive technologies. The results of this study can be used to substantiate long-term state socioeconomic policy measures.

Keywords: noo-society, noonomy, socioeconomic system, fourth industrial revolution, economic evolution, material production, reindustrialization, economic policy.

\section{INTRODUCTION}

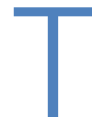
he modern economy is very uneven in its development both in the spatial aspect and by sector and is characterized by instable dynamics with growth rates exhibiting certain fluctuations at medium-term intervals (Table 1).

Table 1: Actual and Forecast Dynamics of Real GDP, \%

\begin{tabular}{|c|c|c|c|c|c|c|c|}
\hline & $\mathbf{2 0 1 5}$ & $\mathbf{2 0 1 6}$ & $\mathbf{2 0 1 7}$ & $\mathbf{2 0 1 8 \mathrm { e }}$ & $\mathbf{2 0 1 9 f}$ & $\mathbf{2 0 2 0 f}$ & $\mathbf{2 0 2 1 f}$ \\
\hline Worldwide, incl. & 2.9 & 2.6 & 3.1 & 3.0 & 2.6 & 2.7 & 2.8 \\
\hline developed countries & 2.3 & 1.7 & 2.3 & 2.1 & 1.7 & 1.5 & 1.5 \\
\hline $\begin{array}{c}\text { emerging markets and } \\
\text { developing countries }\end{array}$ & 3.8 & 4.1 & 4.5 & 4.3 & 4.0 & 4.6 & 4.6 \\
\hline incl. BRICS & 4.0 & 4.6 & 5.3 & 5.4 & 5.1 & 5.3 & 5.3 \\
\hline China & 6.9 & 6.7 & 6.8 & 6.6 & 6.2 & 6.1 & 6.0 \\
\hline Russian Federation & -2.5 & 0.3 & 1.6 & 2.3 & 1.2 & 1.8 & 1.8 \\
\hline India & 8.0 & 8.2 & 7.2 & 7.2 & 7.5 & 7.5 & 7.5 \\
\hline
\end{tabular}

Source: World Bank.

Notes: $\mathrm{e}=$ estimate; $f=$ forecast

On the one hand, uneven development is typical of any large system. But, on the other hand, the current stage of economic development is characterized by dramatic irregularities, which allows for the conclusion that the evolution of the economy is nearing its bifurcation point. In this context, from the perspective of scientific analysis, it is important to forecast the

Author: Professor, President of the Free Economic Society of Russia, President of the International Union of Economists, Director of S.Y. Witte Institute for New Industrial Development. e-mail: inir@inir.ru development dynamics of the socioeconomic system in order to have the possibility to choose the path for further development rationally (which is often impossible in sizable systems comprising a large number of subjects with conflicting interests) or at least influence its trajectory.

Moreover, it is necessary to account for uncertainty embedded in the market economy and also the cyclicity of economic growth rates which, if the aforementioned bifurcation point in its systemic dynamics coincides with a recession, may result in long- 
term stagnation and actuate the negative scenario. An important aspect, which constitutes a fundamental characteristic of the current state of affairs, is the revolutionary change in the dominant technological mode, i.e. the change related to the dynamics of another Kondratieff wave and generally referred to as the Fourth Industrial Revolution [1].

Summing up the aforementioned ideas, we can draw the conclusion about the relevance of the search for new models of socioeconomic system development and organization. Moreover, instead of accounting for minute circumstances, prospective models should rely on long-term fundamental system dynamics. This study seeks to find such a model and provide the theoretical substantiation of its core characteristics.

\section{Sources And Methods}

The study relies on quantitative and qualitative data that reflect the situation in and dynamics of economic development (worldwide and for certain countries and regions). The data are drawn from official reports compiled by statistical services, analytical materials of international organizations (World Bank, World Economic Forum, International Monetary Fund, etc.) and scholarly publications, including the ones reflected in prior original research.

The author's methodology incorporates the Marxist and institutiona list approaches to economic analysis, as well as conventional universal methods (historical, retrospective, comparative, statistical, structural, etc. analysis), systems theory, scenario analysis, forecasting and modeling methods, expert approach, etc.

\section{iil. Results and Discussion}

Accelerated development of science and technologies, which has currently taken the shape of the Fourth Industrial Revolution, is a core premise underpinning the future transformation of the socioeconomic system. By changing the content of core technologies and dramatically increasing operational efficiency, new technologies are ultimately altering not only the structure of the economy, but also public relations. These changes can be seen, for example, in the popular idea that robots will soon replace humans in the economy [2] causing mass unemployment and resulting in other negative social consequences.

Let us point out that in spite of its relevance (particularly for the technologically advanced countries), the issue is hardly new. For example, back in the nineteenth century Karl Marx, who in his economic and social analysis famously prioritized material production, predicted that in the future people would be supplanted from production processes, cease to be their participants and assume the role of "watchmen and regulators." Modern robotics, the Internet of Things and other technological achievements make the future that Marx portended come true.

Under modern conditions, technological changes have become a key factor in socioeconomic transformations, and these changes themselves rely on an increase in the knowledge intensity of material production, whereas an increase in knowledge intensity leads to snowballing changes in the very system of both knowledge and technologies. Acquisition and transformation of new knowledge generates new technologies, and these technologies further serve as the source of new knowledge.

Characteristics of this process that exude a positive reverse effect include higher integration of production, science and education; focus on reindustrialization based on high technologies; reduction in the duration of an innovative cycle; and accelerated diffusion of innovations and penetration of technologies that recently seemed novel (robots, computers, the Internet, new energy sources, nanotechnologies, etc.) not only into production, but also into social processes and people's daily routine. We are observing a shift in the structure of production factors and their significance. The essence of this shift is that knowledge, as opposed to things (physical capital), has become a critical factor in our progress.

This qualitative change in material production engenders a new quality of the economy and society and the formation of the new industrial society of the second generation (NIS.2) [3] based on high-tech knowledge intensive production, which, in turn, harbingers further genesis of a qualitatively new model of economic activity - the noonomy - and the corresponding new social order-the noo-society (Fig.1). 

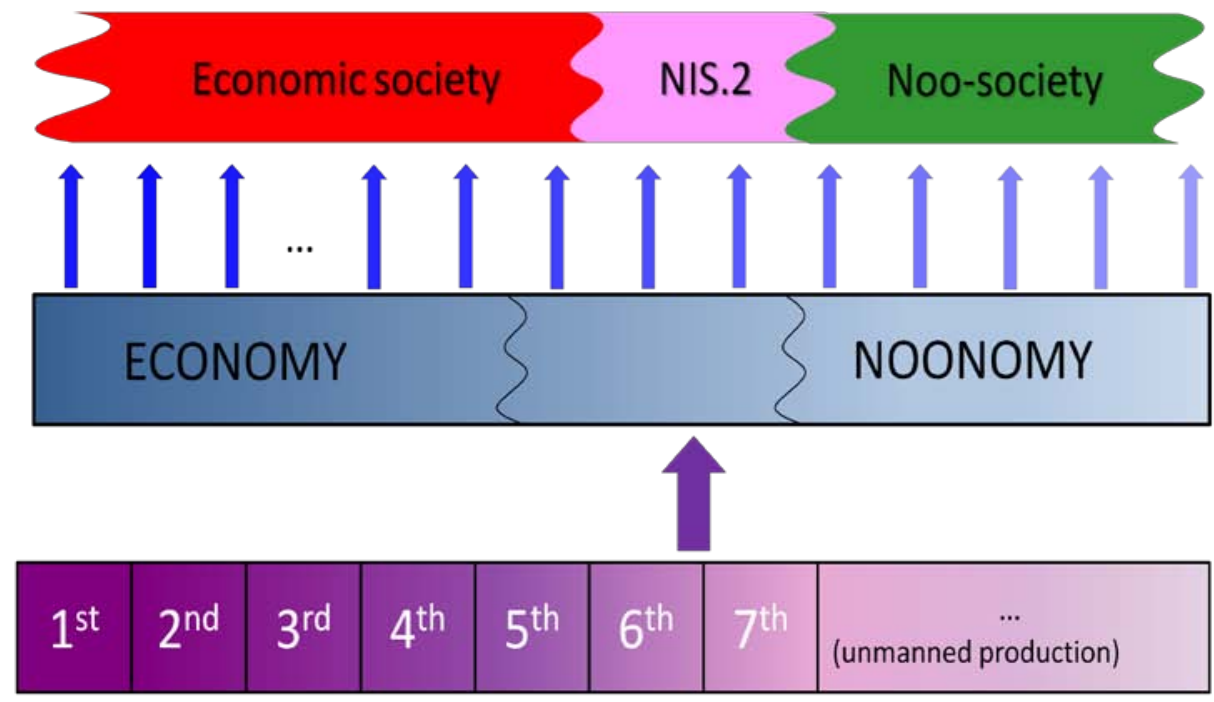

SOCIAL ORDER

\section{TECHNOLOGICAL \\ DEVELOPMENT AND \\ MATERIAL PRODUCTION \\ (MODES)}

Fig. 1: Stages in the Evolution of Economic Activity Models

For a long time, theoretical perceptions of the current stage in the evolution of the socioeconomic system have been operating within the concepts of industrialism and post industrialism [4], and only a representative of institutional economics J.K. Galbraith [5] tried to disprove this logic in his work. Galbraith introduced the concept of the New Industrial State. He believed that industrial development served as the foundation of not only economic, but also public progress. For a while, his ideas were regrettably overlooked by both theoreticians and practitioners.

Nevertheless, many countries are currently exhibiting a renewed interest in industry. Not just developing, but also developed countries are adopting national strategies and programs targeting reindustrialization (new industrialization) [6]. Naturally, that warrants a reconsideration of theoretical approaches to the socioeconomic development. In this respect, we would like to emphasize a number of key points.

First: Production that can be termed 'industrial' based on its core characteristics is not a thing of the past. It is the present and the future. Modern industry, however, is not the same as it used to be not only in the nineteenth, but also the twentieth centuries. The twenty first century engendered and witnessed quick progress of a new type of industry - knowledge intensive industry.

Second: Industrial production that is actively developing today is de facto material production, for knowledge facilitates progress in the society's material life and human qualities. In their development, culture, education and science, which (through reverse influence) are becoming the critical factors in the progress of material production, should all rest on material foundation. In this instance, we observe a close correlation with Marx's views as they pertain to his perception of the social structure as an aggregate of the Base and the Superstructure [7].

Third: It is important to emphasize technological upgrades which account for a qualitatively new format of industrial material production. Production, primarily, comprises labor and the man of labor. These categories bring together economic and social studies, and in real life shape the synergy of the socioeconomic system.

The emphasis on production is important for reforming the management of the economy (applied aspect); moreover, the primacy of production should also be taken into account by economic theory, which requires the integration of new ideas developed by representatives of the neoclassical political economy, institutionalism, Neo-Marxism, world-systems theory, and some other schools of thought into the mainstream.

Figure 2 shows the main points of knowledge intensive economy and corresponding models of industrial production. Knowledge intensity allows for the transformation of the development driver, i.e. innovations (Joseph Schumpeter). The process of technological innovation is undergoing changes towards acquiring the following characteristics: (1) 'acceleration of acceleration', the second derivative of technological upgrades of sorts; and (2) continuity of the innovation process. 


\section{Essential characteristics of knowledge intensive economy:}

- reversed dynamics of the role of materials and knowledge components in knowledge intensive product;

- change in the place and role of humans (human labor) in public production;

- change in the nature of innovative technological activity ('acceleration of acceleration', continuity of the innovation process, etc.)

- sharp increase in the significance, urgency and opportunity for the integration of production, science and education;

- emergence of premises for the formation of the knowing man (homo noosus);

$-\ldots \quad \cdots \quad \ldots$

\section{Fig. 2: Essential Characteristics of Knowledge Intensive Economy}

A new model of the socioeconomic system has a number of specific characteristics.

First, we assert that the postindustrial society described by Daniel Bell and his followers is merely an illusion which both conceals and reveals real issues, for qualitative changes in the economy are indeed imminent, and they are actually related to the development of new technologies. The catch, however, is that these changes should not be seen as signs of the transition to the service society; instead, they manifest qualitative shifts in the technologies of material production and industry per se. Active adoption of these technologies cannot be promoted under the postindustrialist rejection of industrial production; it should be facilitated by pursuing reindustrialization on a qualitatively new technological foundation.

Top global powers have already sprung into action, for they have perceived the need to reverse feckless deindustrialization and the relocation of production facilities to countries which are less technologically advanced. That is why the U.S. and other developed countries are promoting reshoring by reintroducing domestic manufacturing or creating local production facilities. Let us point out that one of the goals pursued by US President Donald Trump in initiating the trade war with China is to ensure the 'return' of production facilities that were moved there by American transnational corporations.

Second, we are witnessing the emergence of the new industrial society of the second generation
(NIS.2), which observes the dialectical 'negation of the negation' principle (J.K. Galbraith's the new industrial state - 'postindustrialist chimeras' - NIS.2) and restores the industry's dominant position in the economy in a new capacity. In this case, the core change lies in the transition towards knowledge intensive material production, which creates a domino effect and causes changes in all areas of production and the economy, such as a sharp decline in the role of material factors in production and an increase in the role of knowledge, 'acceleration of acceleration' of innovative processes, etc.

As a result of progressing down the knowledge intensive path of development (Fig. 3), there comes a point when the knowledge component becomes much larger than the material part in the majority of goods. Our graph illustrates this point really well by showing the intersection of curves which reflect the share of material and intellectual costs in total production spending. 


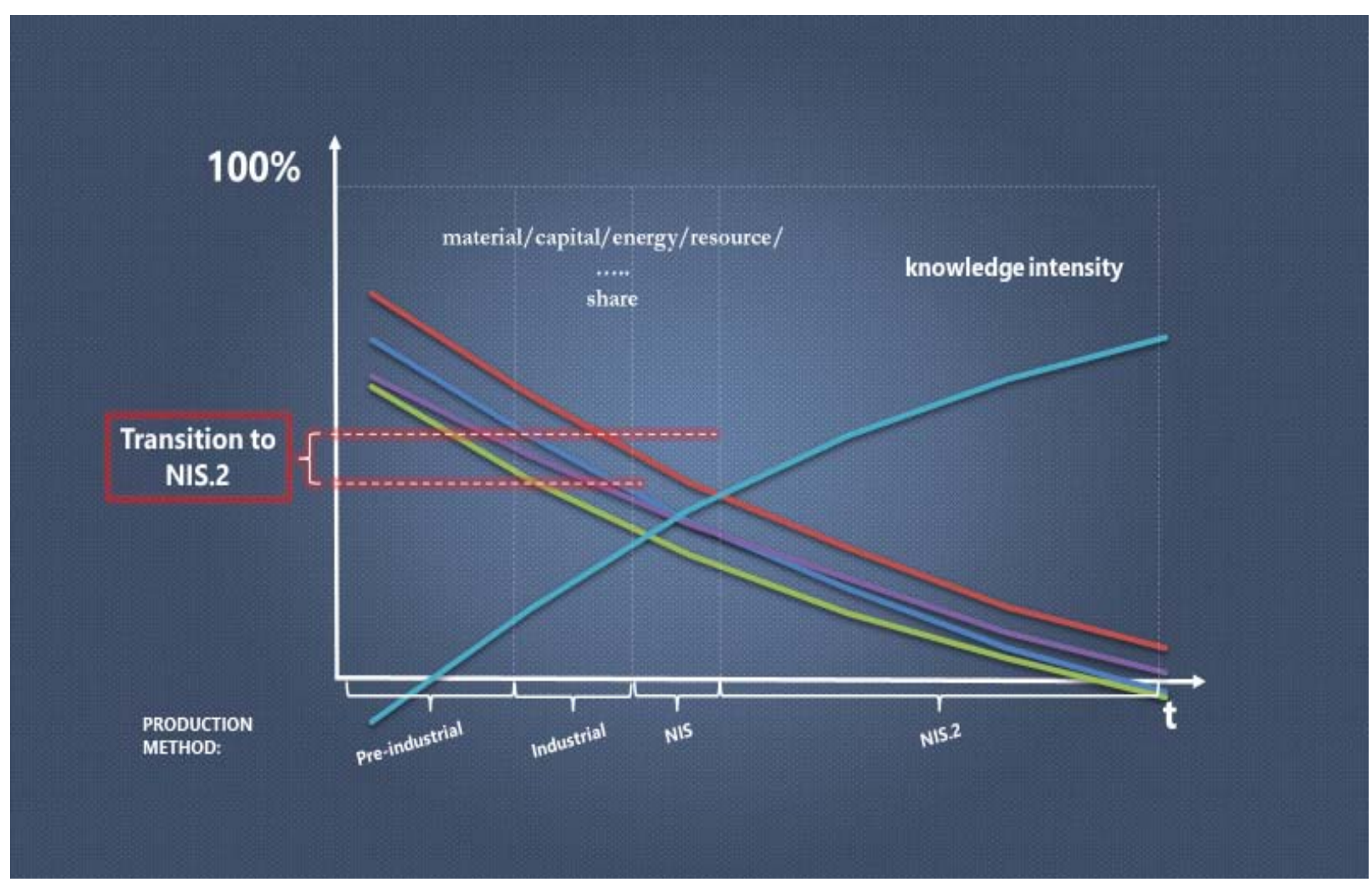

Fig. 3: Historical Change in Unit Utilization Parameters of Product Components

Third, the transition to the NIS.2 necessitates a certain reform in the system of economic relations, which, in turn, stipulates the development and implementation of an active industrial policy, strategic planning, public-private partnership, integration of production, science and education at micro- and macrolevel, etc.

The shift towards the prospective economic model which we refer to as the NIS.2 is not an abstract concept, but an actual process that is vigorously, albeit unevenly, unfolding in various locales of the global economic space. Germany, Japan, the U.S. and China are creating qualitatively different subspaces of new industrial technologies. Therefore, state economic policy should prioritize technological upgrading, acceleration of innovative development and reindustrialization reliant on modern science and cutting-edge technologies.

Not material resources, but knowledge will become the main source and pivotal factor of production development; simulative wants which are dominating the modern society will gradually lose their significance and get replaced with the desire to acquire knowledge; the system of income inequality will be superseded by the system based on unequal talents and aptitudes; and the humanity, which is becoming a powerful geobiological force (according to Vladimir Vernadsky's concept of the noosphere [8]), will have to shift away from the consumption of natural resources to the reproduction of geobiocoenoses. And this list of upcoming changes is far from being exhaustive.
Under this future model of the socioeconomic formation, traditional economic categories and laws (value, property and money) will gradually lose their conventional meaning and might disappear entirely. Thus, all economic forms will naturally evolve into noneconomic ones. The formation of production which does not involve immediate human labor and instead relies on operations performed by technetic beings will lead to the removal of interpersonal economic relations in the technological settings of automated production (Fig. 4). 


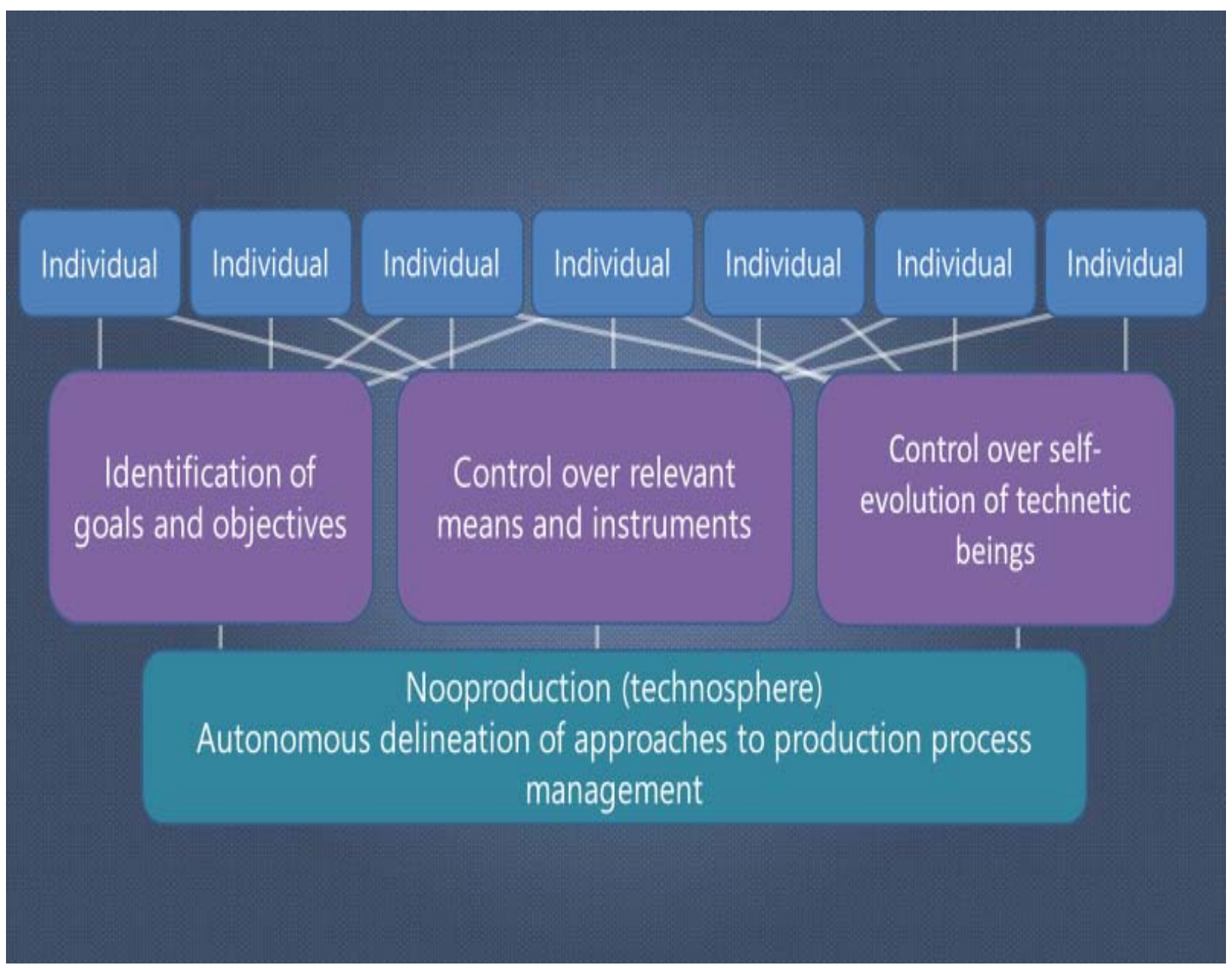

Fig. 4: Human Relations Pertaining to Noo-production Control

The aforementioned transformations will result in the emergence of a qualitatively new phenomenon the noo-society - as a historically new model for public organization, with the noonomy serving as the material foundation of such society. Noonomy refers to a noneconomic way of organizing production relations that ensures the satisfaction of wants and is implemented by humans removed from material production. In other words, the noonomy is a system which is evolving from the economy into a system where people are engaged in relations that shift beyond material production per se into the realm of noo-production [9] (Fig. 5). That is a key distinction between the future system of relations and the conventional economy. 


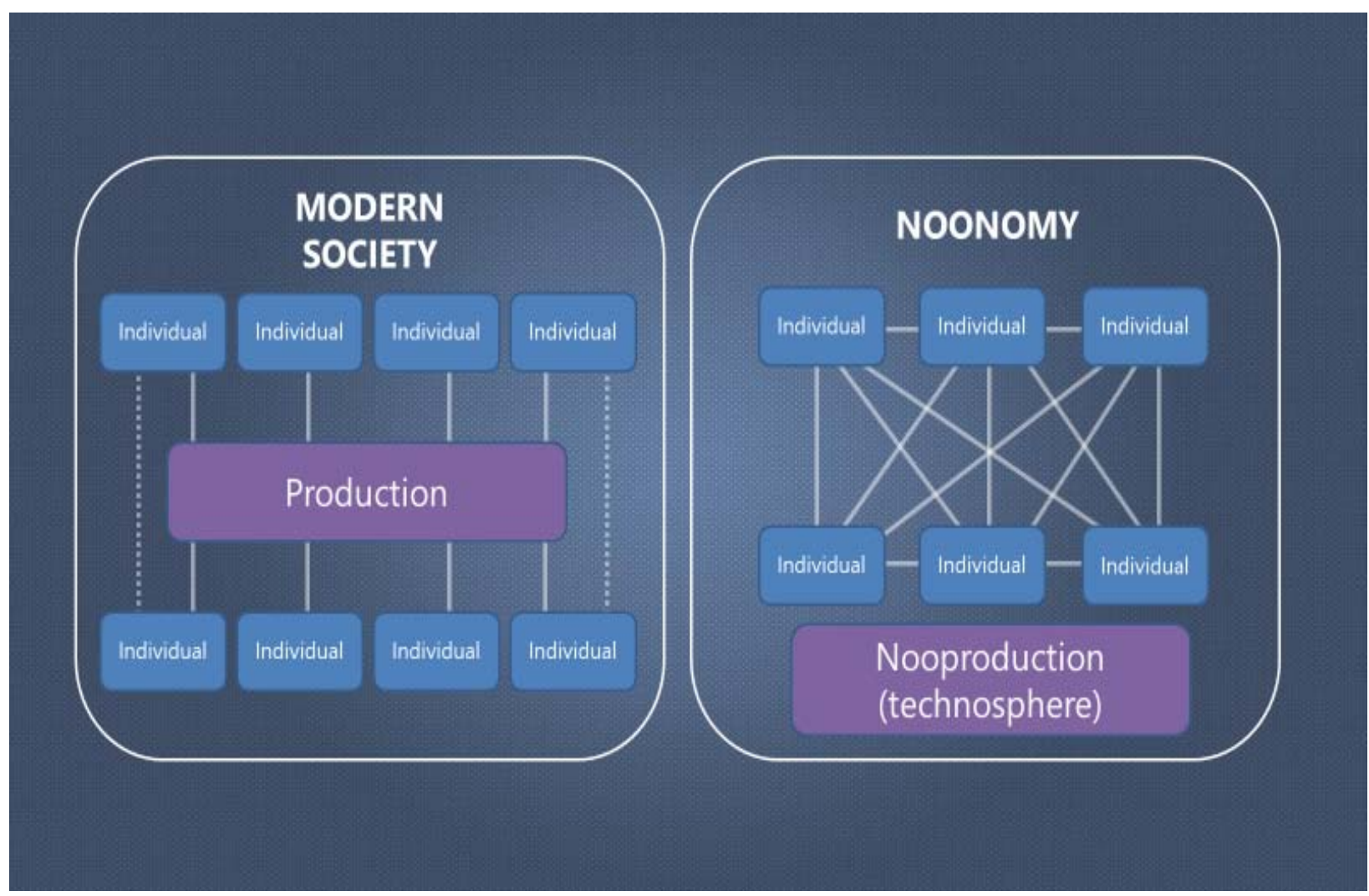

Fig. 5: Historical Change in Public Organization Models

Humans used to create their public institutions and make economic decisions based predominantly on relations associated with the production process, but this is about to change. As we gradually withdraw from immediate production, our activities will be regulated not by interpersonal liaisons between members of the workforce engaged in production, but by the relation between the society as whole and production in general, with production becoming increasingly unmanned.

At the same time, the transition of the human civilization to the noo-society through the NIS.2 is hardly automatic. Such transition does comply with the logic of progressive development, but, historically, objective premises do not necessarily have an immediate effect on the course of events. In real life, the socioeconomic development is greatly affected by momentary factors and various incidents, so the bifurcation point on the path towards the noo-society and noonomy is still ahead of us.

Human civilization is now in jeopardy because, in our pursuit of technology-driven leadership positions under the current expansionist economic development paradigm, we risk wasting the opportunity to establish a rational socioeconomic system reliant on the technological progress and may even lose our human identity. We are facing a choice: (a) move towards the rationalization of development processes, towards the noo-society and noonomy, or (b) follow an invariant of the negative scenario based on idolizing the 'pure market' with all its inherent issues which, as our technological capabilities increase, may have fatal consequences and even lead to a global catastrophe.

We have garnered multiple negative trends in the development of the technosphere. Human habitat and the biological system have been seriously compromised, as we observe the accumulation of issues pertaining to human interaction with the technosphere and an increase in our dependency on the technical and information environment, which results in human cyborgization of sorts.

The history of civilizational development exhibits an accelerated growth of man-made technetic species (strictly in accordance with the 'acceleration of acceleration' of innovations principle) at the expense of quickly declining biodiversity [10]. This trend is particularly pronounced due to the pursuit of profit and fixation on bulk economic indicators which increasingly fail to reflect actual human wants. Resulting higher stress on the environment caused by an increase in simulative wants, ever-growing inefficient use of natural resources and the expansion of mining and processing areas creates a tangible opportunity for the onset of negative consequences.

The world currently finds itself on the verge of a major change in long-term development trends. The situation in the beginning of the twenty first century resembles the early eighteenth century, when world 
leaders distinguished themselves by daring to abandon the traditional ways (executing a qualitative breakthrough by adopting steam, a novel technology at the time, and prioritizing capital and personal freedom); the leaders of our time will be made of those who move beyond the achievement of fetishized economic growth and perform the leap towards knowledge-based production, development of human capital and the pursuit of noo-development.

Instead of focusing on GDP growth, which merely reflects an increase in the amount of manufactured products and services, including simulative goods [11], a new model of socioeconomic development should adopt a set of criteria that will adequately evaluate the satisfaction of specific, rational and reasonable human wants that are critical for further human development.

In order to ensure our progress along the trajectory comprising (a) modern society based on the traditional economy, (b) new industrial society of the second generation (NIS.2) based on knowledge capacity and knowledge intensity of production, and (c)noo-society based on the noonomy (which from the perspective of the socioeconomic and humanitarian progress has no viable alternative), it is necessary to not only engage in active development of technologies and their implementation in industrial (material) production, but also achieve general consensus on the explored agenda through ensuring its exposure and engaging in a wide scholarly and public (civil) discussion.

\section{Conclusion}

The modern world is at a civilizational crossroads. Issues accumulated in the process of socioeconomic development cannot find a satisfactory resolution under the current economic and social theoretical concepts. The study models the main characteristics of the promising trajectory for further historical evolution which comprises the modern society based on the traditional economy, the new industrial society of the second generation (NIS.2) based on knowledge capacity and knowledge intensity of production, and the noo-society based on the noonomy. The author explores the main features of promising models for socioeconomic system organization, conditions required for transitioning to such models and issues which need to be resolved to ensure a successful transition. The relevance of the agenda raised in the paper warrants further research of proposed theoretical constructs, including their closer correlation and integration with existing economic, social and humanitarian theories.

\section{ReFERENCES RéfÉRENCES ReFERENCIAS}

1. Schwab, K.(2016). The Fourth Industrial Revolution. New York: Crown Publishing Group.
2. Carson, E. (2019). Robots could replace humans in a quarter of US jobs by 2030. URL: https://www.cnet.com/news/robots-could-replacehumans-in-a-quarter-of-us-jobs-by-2030.

3. Bodrunov, S. D. (2018). From ZOO to NOO: Man, society and production in the conditions of a new technological revolution. Voprosyfilosofii, 7, 109-118.

4. Bell, D. (1974). The Coming of Post-Industrial Society. New York: Harper Colophon Books.

5. [5] Galbraith, J.K. (2010). The Affluent Society \& Other Writings, 1952-1967. New York: Library of America.

6. Bodrunov, S. and V. Plotnikov. (2017).Institutional structures' influence on the technological development of the economic system. Proceedings of the 30th International Business Information Management Association Conference, IBIMA 2017 Vision 2020:Sustainable Economic Development, Innovation Management, and Global Growth, 26582665.

7. Marx, K. (1859). A Contribution to the Critique of Political Economy. URL: https://www.marxists.org/ar chive/marx/works/1859/critique-pol-economy/index. $\mathrm{htm}$

8. Vernadsky, V. I. (1988). Filosofskiemyslinaturalista. Moscow: Nauka.

9. Bodrunov, S. (2018). Noonomy. Translation of the Russian text prepared for the research seminar "Marx in a high technology era: globalisation, capital and class" (October 26-27, 2018, Cambridge). Moscow-St. Petersburg-London.

10. FAO. (2019). The State of the World's Biodiversity for Food and Agriculture. Ed. by J. Bélanger and D. Pilling. Rome: FAO Commission on Genetic Resources for Food and Agriculture Assessments.

11. OECD. (2005). Is GDP a satisfactory measure of growth? OECD Observer. 246/247, December 2004 -January 2005. URL: http://oecdobserver.org/n ews/archivestory.php/aid/1518/ls_GDP_a_satisfacto ry_measure_of_growth_html\#targetText=If\%20ever \%20there\%20was\%20a,most\%20people\%20swear \%20by\%20it. 